\title{
"Strip-trees": the life after. Responses to bark harvesting of medicinal tree species from Forêt Classée des Monts Kouffé, Benin
}

\author{
Claire Delvaux
}

Supervisor: Patrick Van Damme

Laboratory of Tropical and Subtropical Agriculture and Ethnobotany, Ghent University

Public defence: 15 September 2009

The growing interest for medicinal plants from both international industry and local markets requires proper management of tree bark harvesting from natural forests in order to prevent inappropriate exploitation of target species. The lack of ecological data concerning the responses of tree species to bark harvesting often leads to the overexploitation of medicinal tree species, threatening the essential source of medicines for primary health care of rural populations in Africa.

The first part of this work presents the ecological responses of 12 medicinal tree species after experimental bark harvesting carried out on natural populations in the wild. Bark was harvested from 925 trees belonging to 12 species in 38 woodland sites in Benin in 2004. Trees were debarked following a combination of three factors: (i) season of bark harvesting (during the dry season or during the rainy season); (ii) size class of the tree (three classes of d.b.h.); and (iii) intensity of debarking (seven intensities ranging from $20 \%$ to $100 \%$ of trunk debarked). Over the course of the two-year experiment, every six months measurements were made on each tree to collect information on their reactions: edge growth (regeneration developing from the edge of the wound), sheet growth (regeneration on the surface of the wound), vegetative growth, sensitivity to insect attacks, survival, patterns of re-growth and influence of season, tree size, and intensity of debarking on re-growth. This experimental bark stripping demonstrated the complexity of management due to the variety of factors influencing bark re-growth. Based on our results, we developed a decisional step method to help forest managers to select the best techniques for managing each medicinal tree species. Moreover, studying patterns in bark recovery rate is a pertinent management tool to determine for each species the delay necessary for a specific wound area to close.

The second part of this work presents the anatomical features underlying the trees' reaction to bark harvesting. First, vessels appeared to be very good anatomical indicators of a tree's reactions to stress. The study of vessel size and density notably demonstrated that the impact of bark-stripping is limited to the exact place of wounding, implying that a harvest of up to $75 \%$ of the trunk does not necessarily endanger the tree's life. Nevertheless, recovery of vessel features (size, density) towards their condition before wounding is a slow process that requires at least two years to complete. Second, the width of conducting phloem also proved to be a predictive indication of a tree's ability to close wounds. Given that the 12 species studied showed a broad range of bark recovery rates 
(0.I to $10.0 \mathrm{~cm} / \mathrm{y}$ ), we assume that they are representative for the variety of wound healing responses (i.e. wood and bark tissue production) in a high number of African tree species. Consequently, our results offer the advantage to foresee the potential of wound closure in any tree from which bark could be harvested.
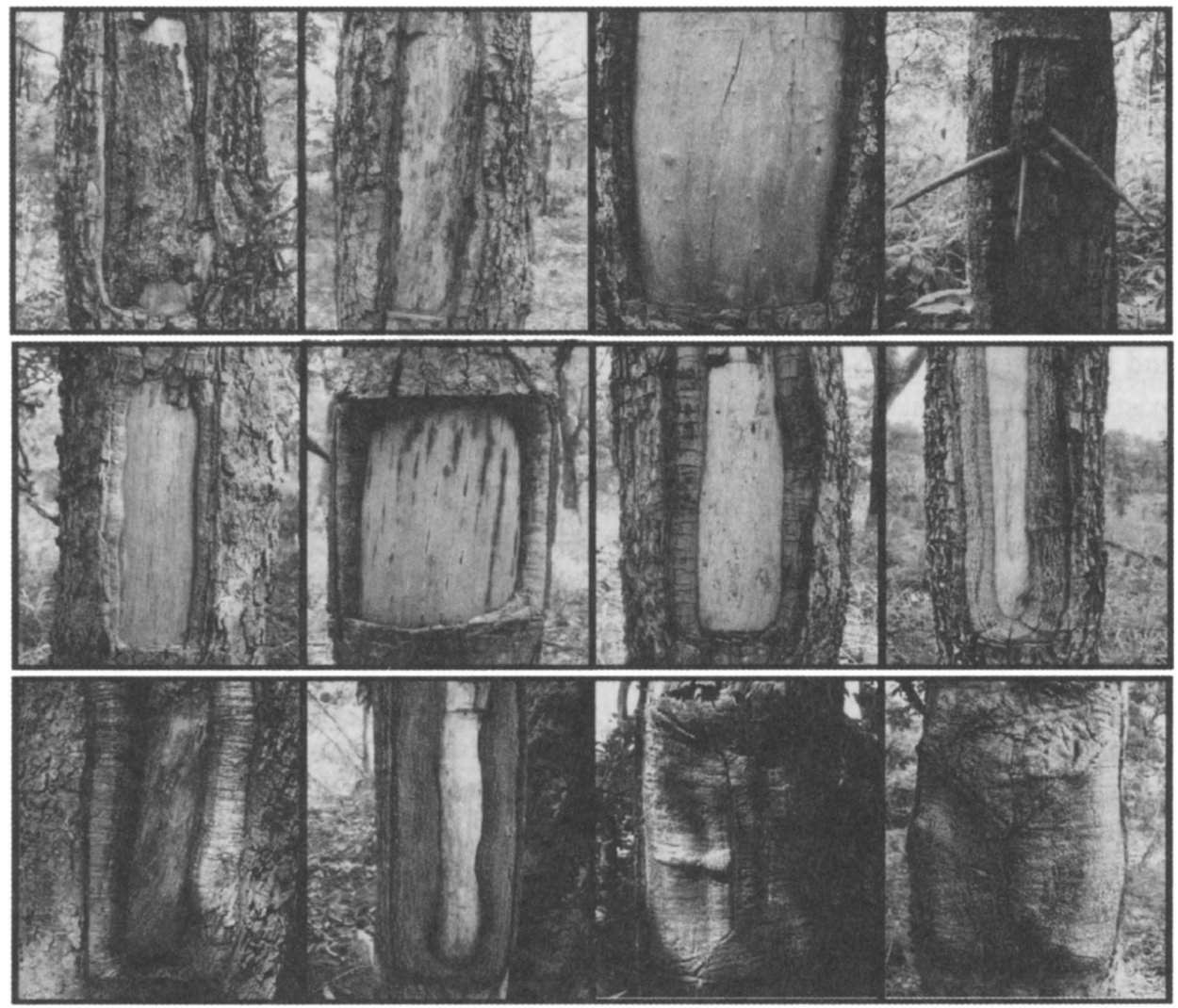

\begin{tabular}{l|l|l|l}
\hline Maranthes polyandra & Afzelia africana & Burkea africana & Uapaca togoensis \\
\hline Lophira lanceoloata & $\begin{array}{l}\text { Detarium } \\
\text { microcarpum }\end{array}$ & $\begin{array}{l}\text { Pterocarpus } \\
\text { erinaceus }\end{array}$ & $\begin{array}{l}\text { Pseudocedrela } \\
\text { kotschyi }\end{array}$ \\
\hline Parkia biglobosa & Mangifera indica & Lannea kerstingii & Khaya senegalensis \\
\hline
\end{tabular}

The bark regeneration of 12 medicinal tree species two years after debarking. Realisation: Claire Delvaux. 